\title{
Note
}

\section{Electrolytic Oxidation of Cyclohexanone in Aqueous Solution}

\author{
Michio SUGAwARA* and Makoto SATO*
}

\section{Introduction}

There are few studies on the electrolytic oxidation of ketones. The authors have studied the electrolytic oxidation of cyclohexanone as an example among ketones.

The electrolytic oxidation of aqueous cyclohexanone gives some carboxylic acids such as adipic acid, maleic acid, etc. ${ }^{1)}$ but a detailed mechanism has not been clarified. Recently, Oyama et al. ${ }^{2)}$ reported that $\gamma$ - and $\delta$-lactones were obtained by the electrolytic oxidation of a sodium bisulfite adduct of cyclohexanone. From the proposed mechanism ${ }^{2}$, the formation of other products, such as $\varepsilon$-lactone and the coupling product of intermediate radicals, are expected but these compounds have not been detected in the electrolyte.

The purpose of this paper is to investigate the electrolytic oxidation of aqueous cyclchexanone in more detail.

\section{Results and Discussion}

In this experiment macro electrolysis at a constant current was mainly carried out for the isolation and analysis of products. The typical results of macro electrolysis under various conditions are shown in Table 1 . The yield of liquid product, consisting of $\mathrm{I} \sim \mathrm{III}$, was shown in $\mathrm{g} / \mathrm{Fr}$ in the table. I, II, and III are $\gamma^{-}, \delta^{-}$, and $\varepsilon$-lactones, respectively. Mol $\%$ of $\mathrm{I} \sim$ III was determined by a gas chromatography.

As shown in the table, I and II were obtained in every runs. The yield of III was usally small and adipic acid (IV) was obtained in the case of the $\mathrm{Pb}$ anode. 1,12-Dodecanedioic acid (V) was also formed as another product in a mixed solvent of acetonitrile and water. Furthermore, the yield of II was larger than I in aqueous sulfuric acid but the yield of $I$ increased in acetonitrile-water and alkaline electrolyte.

From the above results, the reaction process from cyclohexanone to each product can be explained as shown in Fig. 1. Oyama et $a l^{23}$ suggested that the electrolytic oxidation of the sodium bisulfite adduct of cyclohexanone proceeds through cation species. A similar mechanism may be applied to the oxidation of cyclohexa-

Table 1 Macro electrolysis of cyclohexanone in aqueous solution

\begin{tabular}{|c|c|c|c|c|c|c|c|c|}
\hline \multirow{2}{*}{ Anode } & \multirow{2}{*}{ Anolyte } & \multirow{2}{*}{$\begin{array}{l}\text { Concentration of } \\
\text { cyclohexanone } \\
(M / L)\end{array}$} & \multirow{2}{*}{$\begin{array}{l}\text { Current } \\
\text { density } \\
\left(\mathrm{A} / \mathrm{dm}^{2}\right)\end{array}$} & \multirow{2}{*}{$\begin{array}{l}\text { Amount of } \\
\text { current } \\
\text { (Fr) }\end{array}$} & \multirow{2}{*}{$\begin{array}{l}\text { Yield of liquid } \\
\text { product } \\
\qquad(\mathrm{g} / \mathrm{Fr})\end{array}$} & \multicolumn{3}{|c|}{$\begin{array}{l}\text { Relative amount of } \\
\text { lactones (Mol\% })\end{array}$} \\
\hline & & & & & & I & II & III \\
\hline $\mathrm{Pt}$ & $\mathrm{N}-\mathrm{H}_{2} \mathrm{SO}_{4}$ & 3.8 & 2.5 & 0.37 & 3.5 & 23.9 & 72.1 & 4.0 \\
\hline Pt & $\mathrm{N}-\mathrm{H}_{2} \mathrm{SO}_{4}$ & 3.8 & 5 & 0.37 & 4.2 & 18.9 & 77.5 & 3.6 \\
\hline $\mathrm{Pb}$ & $\mathrm{N}-\mathrm{H}_{2} \mathrm{SO}_{4}$ & 3.8 & 2.5 & 0.37 & $8.0^{\mathrm{a})}$ & 17.2 & 82.5 & - \\
\hline $\mathrm{Pt}$ & $\mathrm{CH}_{3} \mathrm{CN}-\mathrm{H}_{2} \mathrm{O}-\mathrm{NaClO}_{4}$ & 1.9 & 2.5 & 0.34 & $8.9^{\mathrm{b})}$ & 47.3 & 50.2 & 2.5 \\
\hline $\mathrm{Pt}$ & $\mathrm{N}-\mathrm{NaOH}$ & 1.9 & 2.5 & 0.34 & 2.3 & 54.2 & 28.2 & 17.6 \\
\hline
\end{tabular}

a) : Other product, adipic acid $(1.4 \mathrm{~g} / \mathrm{Fr}), \mathrm{b})$ : Other product, 1,12 -dodecanedioic acid $(2.6 \mathrm{~g} / \mathrm{Fr})$

* Department of Applied Chemistry, Faculty of Engineering, Yamagata University (Yonezawa, Yamagata) 


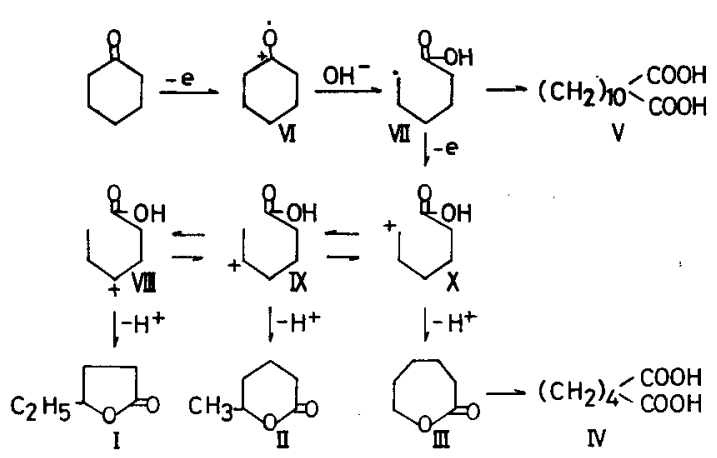

Fig. 1 Reaction process of electrolytic oxidation of cyclohexanone

none from the analysis of the products in macro electrolysis.

Cation radical (VI) is initially formed by one electron transfer from cyclohexanone and then gives radical (VII) by a ring opening and the addition of hydroxide anion. The dimerization of VII yields V. Further one electron transfer from VII leads to form cations (VII, IX, and X), which results in the formation of III, II, and $I$, respectively. The formation of III by the electrolysis of the sodium bisulfite adduct of cyclohexanone has not been reported but $\delta$ valerolactone corresponding to $\mathbb{I I}$ is obtained from cyclopentanone $e^{2)}$.

According to the previous paper, it is analogized that the saturated lactones without substituents are oxidized to the corresponding dicarboxylic acids. In practice, the electrolytic oxidation of $\varepsilon$-caprolactone gave IV with a good yield on $\mathrm{Pb}$ anode, but the yield of $\mathrm{IV}$ was small on $\mathrm{Pt}$ anode. Therefore, IV can be obtained by the electrolytic oxidation of III.

The relative amount of lactones may be affected by the relative stability of cations. It is also considered that the stability of cations depends on the $\mathrm{pH}$ of electrolyte. Furthermore, the above discussion supports strongly that the radical (VII) and cations ( $\mathrm{VII} \sim \mathrm{X})$ are involved in the oxidation process.

Experimental : The electrolytic cell was the $\mathrm{H}$ type with a sintered glass disk diaphragm. Anolyte and catholyte were 80 and $60 \mathrm{ml}$, respectively. $\mathrm{Pt}$ and $\mathrm{Pb}$ plates $(5 \times 4 \mathrm{~cm})$ were used as anode materials. The anolyte was stirred magnetically and maintained at $25^{\circ} \mathrm{C}$ during the electrolysis. The oxidation products were iso- lated and identified as follows.

(1) Electrolysis in sulfuric acid on Pt; After the electrolysis, the anolyte was concentrated under a reduced pressure and then extracted with dichloromethane-diethyl ether. An oily material was obtained after the removal of solvent and separated by means of chromatography on silica gel by using dichloromethane-methyl alcohol as eluant. The first fraction gave II. The second fraction gave the mixture of $\mathrm{I}$ and III, from which only dichloromethane. was chromatographically separated I and III were eluted in that order. I, II, and III were identified by IR spectroscopy and gas chromatography (Triton X-305, $180^{\circ} \mathrm{C}$ ) with authentic samples $^{2,{ }^{25}}$. The adsorption band of $\mathrm{C}=\mathrm{O}$ in IR spectra appeared at I : 1775 , II ; 1740, and III : $1725 \mathrm{~cm}^{-1}$. No carboxylic acid was detected.

(2) Electrolysis in sulfuric acid on $\mathrm{Pb}$; The concentration of anolyte yielded precipitate (IV). The precipitate recrystallized from ethyl alcohol melted at $152 \sim 153^{\circ} \mathrm{C}$ and a mixed melting point with adipic acid showed no depression. IR spectrum of IV agreed with adipic acid. The filtrate was extracted and treated by chromatography in a similar procedure as above. I and II were isolated but III was not detected.

(3) Electrolysis in acetonitrile-water : Sodium perchlorate was used as the supporting electrolyte. After the electrolysis, acetonitrile was evaporated under a reduced pressure and then precipitate (V) was obtained by the acidification with sulfuric acid. The precipitate recrystallized from ethyl alcohol melted at $126 \sim 127^{\circ} \mathrm{C}$ and identified by a mixed melting test and IR spectrum with 1,12-dodecanedioic acid (melting point, $127 \sim 128^{\circ} \mathrm{C}^{3)}$ ). The filtrate was treated as the above procedure and $I \sim$ III were obtained.

(4) Electrolysis in alkaline electrolyte; The anolyte was neutralized with sulfuric acid. No precipitation was obtained by the acidification with sulfuric acid. The concentrated anolyte was treated as the above procedure and $\mathrm{I} \sim$ III were obtained.

(5) Electrolysis of $\varepsilon$-caprolactone: The anolyte was $1.5 \mathrm{M} / l \quad \varepsilon$-caprolactone dissolved in $\mathrm{N}-\mathrm{H}_{2} \mathrm{SO}_{4}$. The current density and amount of current were $2.5 \mathrm{~A} / \mathrm{dm}^{2}$ and $0.54 \mathrm{Fr}$, respectively. After the electrolysis, the anolyte was concentrated under a reduced pressure and gave 
precipitate. The resulting precipitate was identified with adipic acid as above. The yield was $87 \%$ for $\varepsilon$-caprolactone in the electrolysis on $\mathrm{Pb}$ anode and $8 \%$ in the case of $\mathrm{Pt}$ anode.

$<$ E403> (Received Nov. 11,1974)

\section{References :}

1) M. Yokoyama, Bull.Chem. Soc. Japan 8, 71 (19
33).

2) M. Oyama, M. Ohno, Tetrahedron Letters 5201 (1966).

3) M.S. Kharasch, G.W. Sosnovsky, J. Org. Chem. 23, 1322 (1958).

4) M. Sugawara, M. Sato, T. Osuda, H. Yamamoto, This Journal 42, 247 (1974).

5) Y. Ogata, "Yuki Kasankabutsu no Kagaku", p. 127 (1971), Nankodo. 